\title{
Isotope brain scanning with Tc-HMPAO: a predictor of outcome in carbon monoxide poisoning?
}

\author{
M Turner, P M Kemp
}

\section{Department of \\ Cardiology, Derriford \\ Hospital, Plymouth \\ M Turner \\ Nuclear Medicine \\ Department, \\ Addenbrooke's \\ Hospital, Cambridge \\ P M Kemp}

\section{Correspondence to:}

Dr M Turner, Department of

Cardiology, Derriford

Hospital, Plymouth PL6

$8 \mathrm{DH}$.

Accepted for publication 5 February 1997

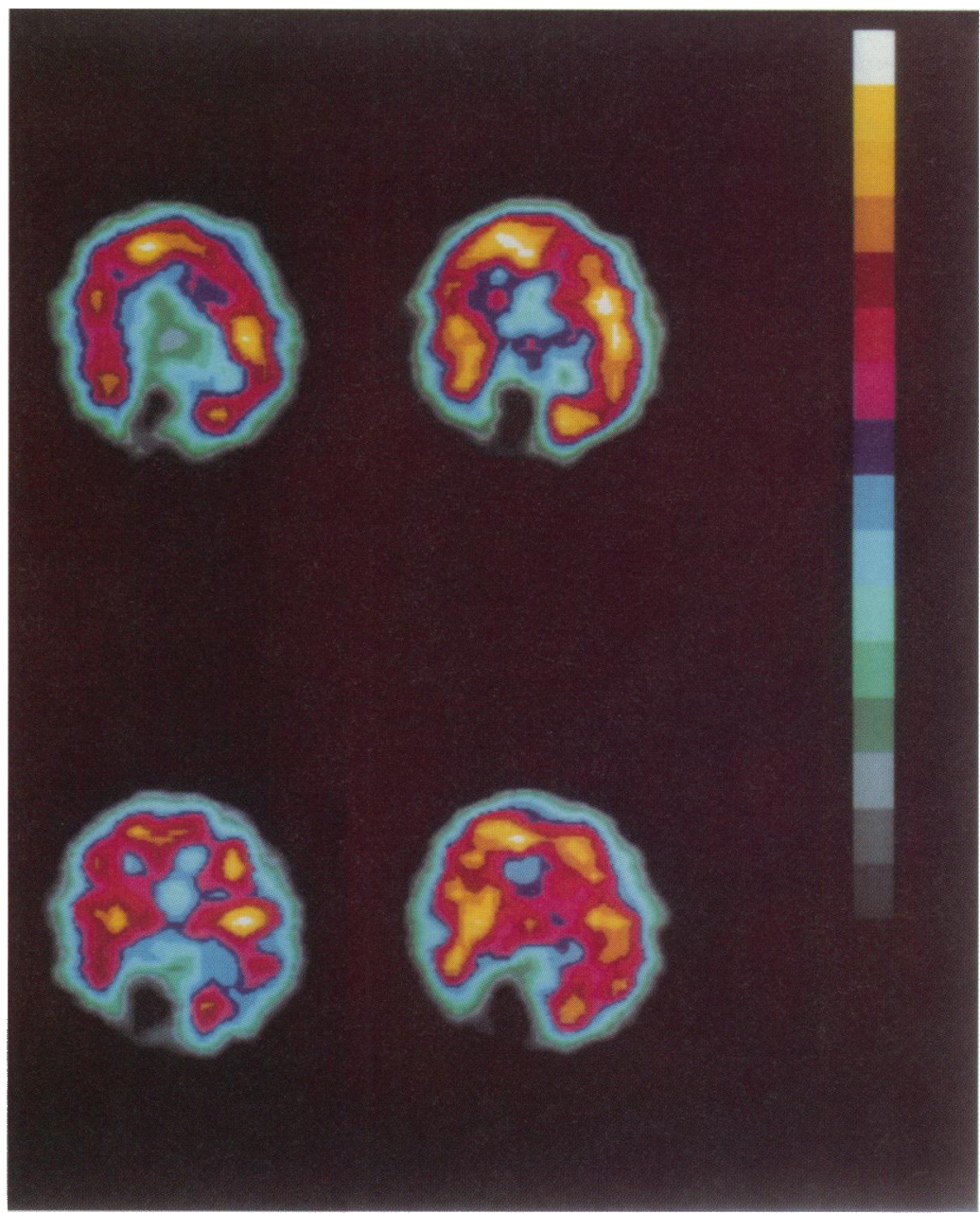

Figure 1 Tc-HMPAO scan in patient 1. Normal cerebral perfusion except for the effect of a birth injury in the occipital lobe.

Keywords: cerebral perfusion imaging; carbon monoxide poisoning; outcome

Carbon monoxide poisoning is a common cause of death by poisoning in the United Kingdom. As well as causing significant immediate mortality and morbidity, new neuro-

\begin{abstract}
Tc-HMPAO isotope brain scans were performed in three patients who received hyperbaric oxygen treatment following carbon monoxide poisoning. Cerebral perfusion imaging provides an index of severity of the initial cerebral damage which correlated with outcome.

(F Accid Emerg Med 1997;14:139-141)
\end{abstract} \section{.} with outcome.
Hyperbaric oxygen therapy may reduce the
incidence of late sequelae. Unfortunately much late morbidity from carbon monoxide poisoning may go unrecognised, ${ }^{8}$ and thus the identification of a high risk group could be helpful. There is evidence that patients presenting with late sequelae respond to hyperbaric oxygen even weeks after intoxication."

We report three cases in which the TcHMPAO isotope brain scan performed during the initial admission and clinical details of outcome were available.

\section{Case 1}

A 40 year old woman was found unconscious, having attempted suicide with car exhaust fumes. The duration of exposure to carbon monoxide was one to two hours. Oxygen was given at the scene. Initial arterial blood gases were as follows: $\mathrm{COHb} 60 \%, \mathrm{pH} 6.96$, base excess -17.6 , bicarbonate 9.1. The Glasgow coma score (GCS) was $5 / 15$ on arrival at the local casualty department and she was intubated and ventilated on $100 \%$ oxygen. She was transferred for hyperbaric oxygen.

\section{Table 1 Manifestations of severe carbon monoxide poisoning}

Neurological
Loss of consciousness
Defects in cognitive function
Focal neurological signs
Cardiovascular
ECG changes
Hypotension
Biochemical
Carboxyhaemoglobin $>20 \%$
Metabolic acidosis




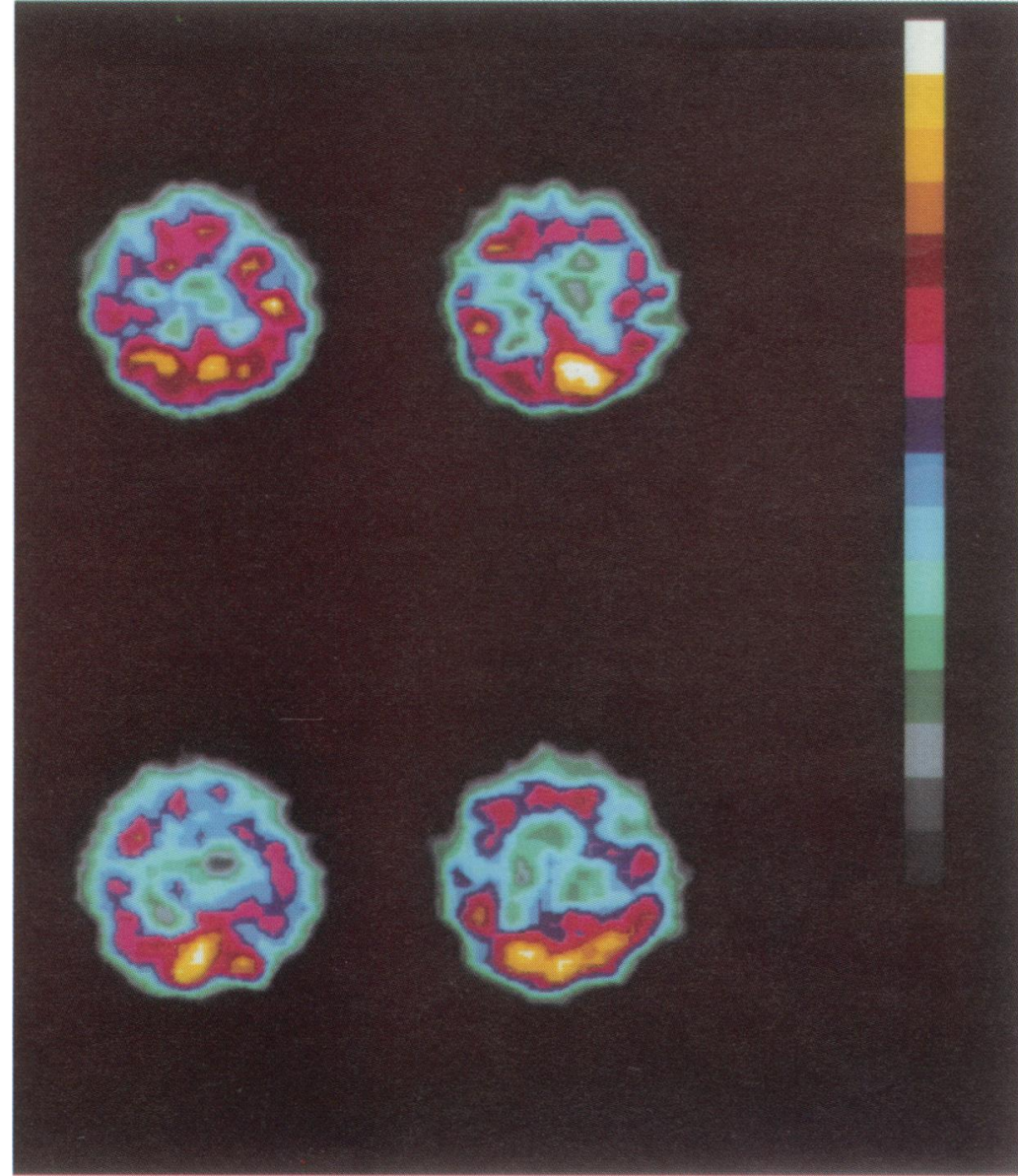

Figure $2 T C-H M P A O$ scan in patient 2. There is diffusely abnormal perfusion.

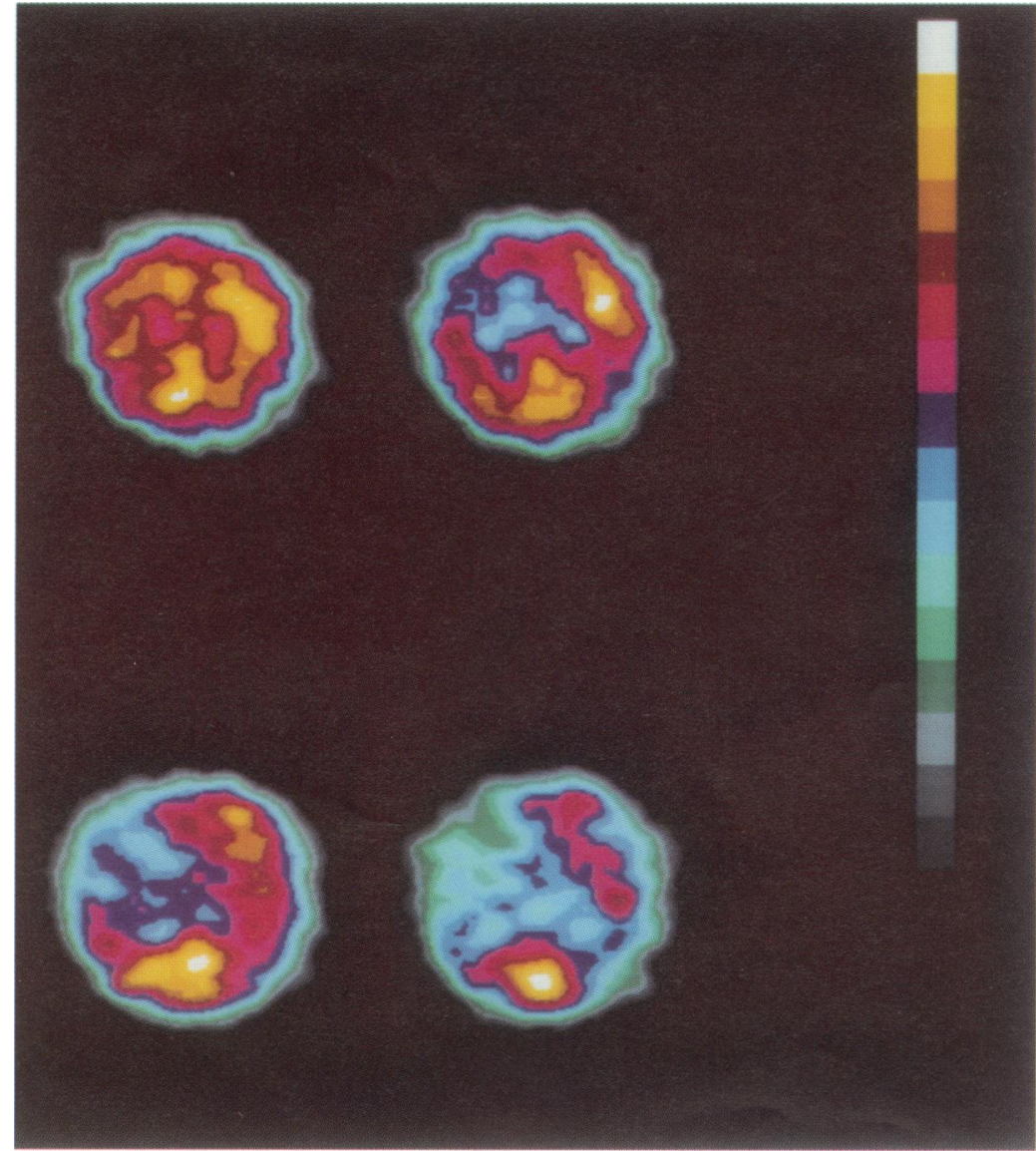

Figure $3 T c-H M P A O$ scan in patient 3. There are focal parietal and frontal abnormalities.
On arrival, GCS was $12 / 15$. Hyperbaric oxygen was given. Tc-HMPAO scan (fig 1) showed an infarcted area corresponding to the right occipital artery territory. Following recovery of consciousness the patient gave a history of left homonymous hemianopia which was due to birth trauma. The isotope uptake in the remainder of the cerebral cortex was normal.

Despite the severely abnormal biochemistry on admission the patient was quickly weaned from the ventilator and recovered fully but remained suicidal.

\section{Case 2}

A 27 year old woman was found having attempted suicide with car exhaust fumes. Duration of exposure was estimated at two hours. On arrival at the local casualty department $\mathrm{COHb}$ was $20 \%$ and GCS $3 / 15$. She was intubated and ventilated on $100 \%$ oxygen and transferred for hyperbaric oxygen within two hours of discovery.

After the first hyperbaric oxygen treatment, GCS was 4/15 (extensor response to pain only) but she was breathing spontaneously. Repeated hyperbaric oxygen treatments were undertaken. On day 4, a Tc-HMPAO brain scan was performed (fig 2). ${ }^{1}$ This showed diffuse abnormalities throughout the brain. The patient died four days later.

Necropsy was undertaken and examination of the brain was reported as follows: "Widespread petechial haemorrhage throughout cerebrum and cerebellum. There was infarction of the undersurface of both temporal lobes."

\section{Case 3}

A 19 year old man was found unconscious in his car. He had regained consciousness by the time of arrival at hospital GCS $15 / 15$, but severe short term memory loss was noted. $\mathrm{He}$ was transferred for hyperbaric oxygen.

Tc-HMPAO brain scan was performed on the day of admission (fig 3$)^{2}$ following treatment. This showed marked bilateral frontal and parietal defects. At the time of discharge his short term memory loss persisted, as assessed by bedside testing. One month after discharge he had a single grand mal seizure. Anticonvulsants were not prescribed and no more seizures have been reported. Follow up three months later revealed that he was receiving treatment from a neuropsychologist who had demonstrated improvement in the short term memory. Unfortunately the patient still had to be accompanied outside his home as he would otherwise get lost.

\section{Discussion}

The three cases reported show an interesting correlation between the appearance of the isotope brain scan and the clinical course.

In case 1, apart from the birth trauma the HMPAO scan was normal and the patient recovered. This is in contrast to case 2 where there were diffuse areas of reduced HMPAO uptake on scanning which were found to represent diffuse damage by necropsy examination.

Our third case shows that isolated neurological deficits can occur following 
carbon monoxide poisoning in association with focal abnormalities on the HMPAO scan consistent with the clinical problem. The reason why some cases develop focal sequelae and others do not is unknown.

Our first two cases also show that the $\mathrm{COHb}$ level is not always a helpful measure of severity and does not always correlate well with outcome. For example, case 1 had a much higher $\mathrm{COHb}$ than case 2 . It is the tissue poisoning with $\mathrm{CO}$, bound to cytochromes and other oxygen carrying proteins, that appears to determine the severity of poisoning, not the level of $\mathrm{COHb}$ in the blood. ${ }^{10} \mathrm{~A}$ patient with low levels of $\mathrm{COHb}$ in the blood may have significant tissue poisoning with $\mathrm{CO}$ and may respond to hyperbaric oxygen. An index of tissue $\mathrm{CO}$ level is not currently available.

The isotope scan with Tc-HMPAO depends on uptake of the isotope by the cells of the brain and is dependent on both blood flow and uptake pathways. Although the precise pathways are still ill defined, isotope uptake certainly reflects blood flow and may reflect the activity of the cerebral energy producing pathways and give an index of severity of cellular poisoning.

In patients presenting with late sequelae, the isotope scans showed diffuse patchy hypoperfusion which improved if the clinical features resolve. ${ }^{6}$ Two patients died in this study but no record of the necropsy findings was made. The patients we describe were scanned soon after the insult rather than when late sequelae occurred.

In a study of Tc-HMPAO scanning performed on the day of admission, focal abnormalities were seen in five out of 12 patients. ${ }^{11}$ These were localised to the temporo-occipital and parieto-occipital cortex and no scans showed diffuse perfusion abnormality. No correlation between these abnormalities and outcome was attempted.

It appears from these three cases that cerebral perfusion imaging provides an index of severity of the initial cerebral damage which correlated with outcome. A prospective evaluation of sequential HMPAO scanning after presentation with carbon monoxide poisoning is planned.

1 Broome JR, Pearson RR, Skrine H. Carbon monoxide poisoning forgotten not gone! Br J Hosp Med 1988;39:298305.

2 Gorman DF, Clayton D, Gilligan JE, Webb RK. A longitudinal study of 100 consecutive admissions for carbon monoxide poisoning to The Royal Adelaide Hospital. Anaesth Intensive Care 1992;20:311-6.

3 Norkool DM, Kirkpatrick IN. Treatment of acute carbon monoxide poisoning with hyperbaric oxygen A review of 115 cases. Ann Emerg Med 1985;14:1168-71.

4 Sawada Y, Takahashi M, Ohashi N, Fusamoto H, Maemura $\mathrm{K}$, Kobayashi $\mathrm{H}$, et al. Computerised tomography as an indication of long-term outcome after acute carbon monoxide poisoning. Lancet 1980;i:783-4.

5 Pracyk JB, Stolp BW, Fife CE, Gray L, Piantodosi CA. Brain computerised tomography after hyperbaric oxygen therapy for carbon monoxide poisoning. Undersea Hyperbaric for carbon monoxid.

6 Choi IS, Kim SK, Lee SS, Choi YC. Evaluation of outcome of delayed neurological sequelae after carbon monoxide poisoning by technetium- $99 \mathrm{~m}$ hexamethylpropylene amine oxime brain single photon emission computed tomography. Eur Neurol 1995;35:137-42.

7 Tibbles PM, Perrotta PL. Treatment of carbon monoxide poisoning: a critical review of human outcome studies comparing normobaric oxygen with hyperbaric oxygen. Ann Emerg Med 1994;24:269-76.

8 Smith JS, Brandon S. Morbidity from acute carbon monoxide poisoning at three-year follow-up. BMJ 1973;i:318-20.

9 Myers RAM, Snyder SK, Emhoff TA. Subacute sequelae of carbon monoxide poisoning. Ann Emerg Med 1985;14: carbon $1163-7$.

10 Goldbaum LR, Orellano T, Dergal E. Mechanism of the toxic action of carbon monoxide. Ann Clin Lab Sci 1976;6:372-6.

11 Denays R, Makhoul E, Dachy B, Tondeur M, Noel P, Ham $\mathrm{HR}$, et al. Electroencephalographic mapping and ${ }^{99 \mathrm{~m}} \mathrm{Tc}-$ HMPAO single-photon emission computed tomography in carbon monoxide poisoning. Ann Emerg Med 1994;24: 947-52. 